ISSN 0103-5150

Fisioter. Mov., Curitiba, v. 23, n. 2, p. 239-250, abr./jun. 2010

Licenciado sob uma Licença Creative Commons

\title{
Caracterização dos fatores ambientais e o controle cervical de lactentes nascidos pré-termo
}

\author{
Characterization of the environmental factors and pre-term \\ infants' cervical control
}

\section{Liziane Cristina Pretti ${ }^{[a]}$, Juliana Cristina Milan ${ }^{[b]}$, Mariana Aparecida Foschiani ${ }^{[c]}$, Elaine Pereira Raniero $^{[\mathrm{d}]}$, Karina Pereira ${ }^{[\mathrm{e}]}$}

[a] Fisioterapeuta, Centro Universitário de Araraquara (Uniara), Jaboticabal, SP - Brasil, e-mail: lizianepretti@hotmail.com

[b] Fisioterapeuta, Centro Universitário de Araraquara (Uniara), São Carlos, SP - Brasil, e-mail: juliana_milan10@hotmail.com

[c] Fisioterapeuta, Centro Universitário de Araraquara (Uniara), Nova Europa, SP - Brasil, e-mail: marianafoschiani@hotmail.com

[d] Fisioterapeuta, Mestre em Processos Básicos, Desenvolvimento e Recuperação Funcional do Sistema Nervoso Central, com ênfase em Neuropediatria pela Universidade Federal de São Carlos (UFSCar), Araraquara, SP - Brasil, e-mail: laristhil@hotmail.com

[e] Professor adjunto do Curso de Fisioterapia, Universidade Federal do Triângulo Mineiro (UFTM), Uberaba, MG - Brasil, e-mail: laristhil@hotmail.com

\section{Resumo}

Objetivo: Caracterizar os fatores ambientais e a aquisição do controle cervical dos lactentes nascidos pré-termo, de recém-nascido aos 4 meses de idade corrigida, nas posturas prona e sentada. Metodologia: Participaram do estudo 18 lactentes, sendo 9 pré-termo (33 semanas \pm 2 semanas) e 9 a termo (39 semanas \pm 1 semana). Foi aplicado o Test of Infant Motor Performance (TIMP), para avaliar o controle cervical dos lactentes, e um questionário para as mães, mês a mês. Resultados: Não houve diferença significativa no desenvolvimento do controle cervical entre os grupos no decorrer dos meses, mas os lactentes nascidos a termo apresentaram escore superior ao pré-termo nos itens 32, 35 e 36 da escala TIMP na idade de recém-nascido. Conclusão: Sugere-se que a diferença de escore na idade de RN entre os grupos pode estar relacionada tanto com as alterações orgânicas que os lactentes pré-termo apresentam quanto aos fatores ambientais.

Palavras-chave: Desenvolvimento motor. Posturas. Prematuridade. 


\begin{abstract}
Objective: To characterize the environmental factors and the acquisition of cervical control by preterm infants, from newborn to 4 months of corrected age, in the prone and sitting positions. Methodology: The study included 18 infants, 9 preterm (33 weeks \pm 2 weeks) and 9 term (39 weeks \pm 1 week). We applied the Test of Infant Motor Performance (TIMP) to evaluate infants' cervical control and a questionnaire to the mothers every month. Results: No significant differences in the cervical control development were found between the groups over the months, but the term infants had a high TIMP score in comparison with the preterm group in items 32, 35 and 36 in newborn age. Conclusion: It's suggested that the difference in score at the age of newborn between the groups may be related to the both organic changes, that preterm has, such as the environmental factors.
\end{abstract}

Keywords: Motor development. Postures. Prematurity.

\title{
Introdução
}

A base de conhecimento do estudo do desenvolvimento motor tem crescido, visando a entender como os lactentes se adaptam às restrições intrínsecas (características físicas, neurológicas e comportamentais) e extrínsecas (objeto, tarefa e contexto) com o decorrer da idade (1-3). Surgiu na década de 1980 uma nova abordagem para o desenvolvimento motor, a Perspectiva dos Sistemas Dinâmicos, segundo a qual a coordenação e o controle do movimento são resultados da interação de vários sistemas trabalhando dinamicamente (4). Tais alterações ocorrem ao longo do tempo e individualmente, sendo influenciadas por fatores intrínsecos e extrínsecos, que podem promover ou inibir as aquisições do desenvolvimento neuro-sensório-motor $(5,6)$.

O lactente pré-termo, nascido antes de 36 semanas de gestação, apresenta dificuldades para adquirir habilidades motoras fundamentais, atraso na aquisição da linguagem e problemas de coordenação motora (7-9). Dessa forma, é importante fazer a correção da idade nos lactentes nascidos pré-termo durante o primeiro ano de vida, para que não haja comparações errôneas sobre sua evolução neuro-sensório-motora, pressupondo que ele pode encontrar-se em atraso quando de fato está normal (10-12).

Várias pesquisas têm se dirigido aos efeitos do comportamento dos pais no período pré-natal e no início da infância, pois influenciam no funcionamento subsequente das crianças. O desenvolvimento posterior é influenciado pelos inúmeros cuidados paternos e maternos associados à extrema dependência dos lactentes. Entre os mais decisivos estão a privação ambiental, o temperamento da criança, vínculos que ocorrem entre os pais e o lactente nos primeiros dias após o nascimento e a posição do lactente durante o sono e em estado de alerta (4).

Em relação à aquisição do controle cervical, ao nascer, o bebê tem pouco controle da cabeça, por causa da fraqueza dos músculos do pescoço, e com o passar dos meses consegue vencer a força da gravidade, mantendo o controle da cabeça por mais tempo nas posturas prona, sentada e em pé (10). Segundo Majnemer e Bar (13), os lactentes que permanecem em supino ao dormir apresentam atraso na aquisição de habilidades motoras que exigem maior controle antigravitacional, ao passo que a posição prona atua como um estímulo para o desenvolvimento de força da musculatura extensora de cervical e tronco.

O recém-nascido pré-termo comumente mostra atraso em seu desenvolvimento, pelo fato de apresentar tônus tipicamente hipotônico ao nascer, adotando posturas em extensão quando em supino, em vez de assumir postura flexora, característica do recém-nascido a termo. Este padrão postural acarreta um atraso na aquisição do controle cervical (10).

Dessa forma, o presente estudo teve como objetivo caracterizar o ambiente de lactentes pré-termo quanto a fatores como estresse materno, uso de nicotina, prática de atividade física, tipo de parto, amamentação, problemas respiratórios, nível socioeconômico, a postura do lactente ao dormir e em estado de alerta e a interação com cuidador principal. Além disto, pretendeu-se avaliar a aquisição do controle cervical dos lactentes nascidos pré-termo em relação aos a termo, nos primeiros 4 meses de idade (corrigida para o grupo 
pré-termo), nas posturas prona e sentada, com a aplicação do Test of Infant Motor Performance (TIMP) (14). Esses resultados serão importantes para orientar os cuidadores quanto à melhor forma de posicionar o lactente ao dormir e em estado de alerta, bem como de estimular o lactente de modo a potencializar suas aquisições motoras ao longo do seu desenvolvimento motor.

\section{Materiais e métodos}

\section{Participantes}

Participaram do estudo 18 lactentes, sendo 9 nascidos pré-termo e 9 nascidos a termo. Todos foram avaliados nas idades de recém-nascido, 1, 2, 3 e 4 meses, sendo feita a correção da idade gestacional nos nascidos pré-termo. Nesse grupo, sete são do sexo masculino e dois do sexo feminino, com média de peso ao nascer de $2,024 \mathrm{~kg}( \pm 583 \mathrm{~g})$ e altura de $41 \mathrm{~cm}( \pm 1,66 \mathrm{~cm})$, média de Apgar 7 e 8 no primeiro e quinto minutos, respectivamente, e média de idade gestacional de 33 semanas ( \pm 2 semanas). No grupo de lactentes nascidos a termo, sete são do sexo feminino e dois do sexo masculino, com média de peso ao nascer de $3,343 \mathrm{~kg}( \pm 471 \mathrm{~g})$ e altura média de $48 \mathrm{~cm}( \pm 1,96 \mathrm{~cm})$, média de Apgar 8 e 9 no primeiro e quinto minutos, respectivamente, e média de idade gestacional de 39 semanas ( \pm 1 semana).

\section{Critérios de inclusão, exclusão e descontinuidade}

Foram incluídos lactentes classificados como pré-termo de acordo com a idade gestacional ao nascer, de 28 semanas até 36 semanas e 6 dias de idade gestacional (7), e lactentes nascidos a termo, de 37 até 40 semanas de idade gestacional (7), ambos com peso adequado para a idade gestacional (AIG), isto é, peso de nascimento entre o percentil 10 e 90 na curva de crescimento (15). Foram requisitos também escores de Apgar maiores que 7 no primeiro e quinto minutos (16) e crianças cuja participação na pesquisa tenha sido aprovada pelos pais ou responsáveis, que assinaram o Termo de Consentimento Livre e Esclarecido.

De ambos os grupos foram excluídos aqueles que apresentaram alterações congênitas no sistema nervoso central e músculo-esquelético, bem como diagnóstico de síndrome genética ou sintomas de crise de abstinência associada a relato de abuso materno de álcool e drogas. Outras causas de exclusão foram sorologia positiva para infecções gestacionais, lesões do sistema nervoso central e déficits sensoriais durante o período neonatal. No decorrer do estudo foram excluídos lactentes que não compareceram a duas avaliações consecutivas; apresentaram intercorrências clínicas ou desenvolvimento motor atípico que influenciariam nos resultados do estudo.

\section{Local de coleta de dados}

As avaliações foram realizadas na residência dos lactentes, de forma a possibilitar observá-los em seu ambiente habitual.

\section{Métodos de avaliação}

As avaliações foram realizadas por meio da aplicação do questionário às mães, a respeito da gravidez, parto e pós-parto, para coletar informações sobre fatores ambientais como: estresse materno, tipo de parto, amamentação, nível socioeconômico, alimentação da criança, problemas respiratórios, postura da criança e em que ambientes permanece, interação com o cuidador principal ou outro ambiente. 
O desenvolvimento do controle cervical foi avaliado com a aplicação do TIMP (14). Essa escala permite avaliar o desenvolvimento do controle postural de lactentes pré-termo nas posições prona, supina, sentada e em pé, visando a detectar possíveis atrasos no desenvolvimento motor típico e atípico, de recémnascido a 4 meses de idade.

Para este estudo foram selecionados os dez itens relacionados ao controle cervical nas posturas prona e sentada, denominados assim de Escore Parcial da TIMP, sendo eles: E14: rotação da cabeça para ambos os lados (sustentado sentado); E15: controle de cabeça na posição sentada; E16: controle de cabeça - músculos posteriores do pescoço (sustentado sentado); E17: controle de cabeça - músculos anteriores do pescoço (sustentado sentado); E18: controle de cabeça - transição de sentado para deitado (sustentado sentado); E32: puxado para sentar; E35: suspensão em prono; E36: levantar a cabeça em prono; E41/42: retificação lateral da cabeça (suspensão vertical).

Foram utilizados alguns brinquedos (um chocalho, um brinquedo musical e uma bola vermelha brilhante) para estimular os movimentos dos lactentes nas diferentes posições durante a realização dos testes. Algumas avaliações foram desconsideradas, pois os lactentes apresentaram-se instáveis (choro).

\section{Procedimentos}

O projeto foi aprovado pelo Comitê de Ética em Pesquisa (Resolução 196/96) com o Parecer 669/07, e os lactentes, selecionados pelos prontuários na Irmandade da Santa Casa de Misericórdia da cidade.

Após entrar em contato com os responsáveis, convidando-os a participar, os objetivos e procedimentos foram esclarecidos e a data de avaliação agendada respeitando cinco dias antes ou após a data de aniversário do lactente.

Neste estudo de caráter longitudinal e prospectivo, todos os lactentes foram avaliados mensalmente, de recém-nascidos ao quarto mês, totalizando cinco avaliações.

Todas as observações e procedimentos de testes foram realizados quando o lactente estava nos estados 3, 4 e 5 de Brazelton (17). Caso o lactente chorasse, o responsável poderia acalmá-lo, no entanto, não sendo possível, o teste seria completado dentro de $24 \mathrm{~h}$, respeitando as normas da TIMP.

\section{Análise estatística}

Os softwares utilizados para as análises foram o SPSS 13.0 e o GraphPad 3.05. Como a escala de medida da TIMP é ordinal, as análises foram realizadas por método não-paramétrico. O teste não-paramétrico utilizado foi o Teste de Mann-Whitney para analisar os escores da TIMP intergrupos, nas idades recém-nascido a 4 meses. Considerou-se a significância de 5\% para as análises.

\section{Resultados}

\section{Caracterização dos fatores externos nos grupos pré-termo e a termo}

$\mathrm{Na}$ Tabela 1 verifica-se que houve maior índice de estresse durante a gestação no grupo de mães de lactentes nascidos pré-termo (44,4\%), em relação ao grupo a termo (42,9\%). O uso de nicotina durante a gestação esteve presente em ambos os grupos, porém obteve maiores índices no grupo a termo (28,6\%). As mães dos lactentes nascidos pré-termo foram as que mais realizaram algum tipo de atividade física regular durante a gestação, como caminhada (33,3\%).

Em relação ao nascimento, a maioria do grupo pré-termo nasceu de parto cesárea $(88,9 \%)$, enquanto no grupo a termo houve alternância entre o parto cesárea (42,9\%) e normal (14,3\% de uso de fórceps). A alimentação do grupo a termo foi exclusivamente de leite materno; já no grupo pré-termo 
houve variações quanto ao aleitamento. O grupo pré-termo foi o único a apresentar algum tipo de problema respiratório $(22,2 \%)$.

No âmbito socioeconômico (18), ambos os grupos apresentaram variações entre as classes B, C e D.

Tabela 1 - Caracterização dos fatores ambientais do grupo prétermo $(\mathrm{n}=9)$ e a termo $(\mathrm{n}=9)$

\begin{tabular}{|c|c|c|c|}
\hline \multicolumn{2}{|c|}{ Fatores ambientais } & $\%$ pré-termo & $\%$ a termo \\
\hline \multicolumn{2}{|c|}{ Estresse durante a gravidez } & 44,4 & 42,9 \\
\hline \multicolumn{2}{|c|}{ Uso de nicotina } & 11,1 & 28,6 \\
\hline \multicolumn{2}{|c|}{ Prática de atividade física } & 33,3 & 28,6 \\
\hline \multirow{3}{*}{ Tipo de parto } & Normal & 11,1 & 42,9 \\
\hline & Cesárea & 88,9 & 42,9 \\
\hline & Fórceps & 0 & 14,3 \\
\hline \multirow{3}{*}{ Alimentação } & Seio & 33,3 & 100 \\
\hline & NAN & 55,6 & 0 \\
\hline & Em pó & 11,1 & 0 \\
\hline \multicolumn{2}{|c|}{ Problemas respiratórios } & 22,2 & 0 \\
\hline \multirow{5}{*}{ Abipeme } & A & 0 & 0 \\
\hline & $\mathrm{B}$ & 42,9 & 33,3 \\
\hline & $\mathrm{C}$ & 28,6 & 50,0 \\
\hline & $\mathrm{D}$ & 28,6 & 16,7 \\
\hline & $\mathrm{E}$ & 0 & 0 \\
\hline
\end{tabular}

$\mathrm{Na}$ Tabela 2 é possível notar as variações de posturas dos lactentes em estado de alerta no decorrer dos quatro meses de avaliações. A postura adotada por ambos os grupos, em recém-nascidos e no primeiro mês de idade, foi preferencialmente no berço, de lado (decúbito lateral). No decorrer dos meses houve alternância de posturas nos dois grupos, sendo que no segundo mês o grupo pré-termo permaneceu preferencialmente em supino, no colo de seus cuidadores $(55,6 \%)$, e o grupo a termo, em supino no carrinho $(66,7 \%)$. No terceiro e quarto mês, o grupo pré-termo permaneceu em supino na rede $(33,3 \%$ em ambos os meses). Já o grupo a termo, no terceiro mês permaneceu em supino no carrinho $(22,2 \%)$ e no quarto mês, em supino no colo $(33,3 \%)$. 
Pretti LC, Milan JC, Foschiani MA, Raniero EP, Pereira K.

Tabela 2 - Caracterização da postura em estado de alerta em ambos os grupos mensalmente

\begin{tabular}{|c|c|c|c|c|c|c|c|c|c|c|}
\hline \multirow{2}{*}{$\begin{array}{l}\text { Postura } \\
\text { em alerta }\end{array}$} & \multicolumn{2}{|c|}{$\mathbf{R N}$} & \multicolumn{2}{|c|}{1 mês } & \multicolumn{2}{|c|}{2 mês } & \multicolumn{2}{|c|}{3 mês } & \multicolumn{2}{|c|}{4 mês } \\
\hline & $\begin{array}{l}\% \text { pré- } \\
\text { termo }\end{array}$ & $\begin{array}{c}\% \text { a } \\
\text { termo }\end{array}$ & $\begin{array}{l}\% \text { pré- } \\
\text { termo }\end{array}$ & $\begin{array}{c}\% \text { a } \\
\text { termo }\end{array}$ & $\begin{array}{l}\% \text { pré- } \\
\text { termo }\end{array}$ & $\begin{array}{c}\% \text { a } \\
\text { termo }\end{array}$ & $\begin{array}{l}\% \text { pré- } \\
\text { termo }\end{array}$ & $\begin{array}{c}\% \text { a } \\
\text { termo }\end{array}$ & $\begin{array}{l}\% \text { pré- } \\
\text { termo }\end{array}$ & $\begin{array}{c}\% \text { a } \\
\text { termo }\end{array}$ \\
\hline $\begin{array}{l}\text { No berço } \\
\text { (barriga p/ baixo) }\end{array}$ & 33,3 & - & 33,3 & - & - & - & 11,1 & - & 11,1 & - \\
\hline $\begin{array}{l}\text { No berço } \\
\text { (barriga p/ cima) }\end{array}$ & - & - & - & - & - & - & - & - & - & - \\
\hline $\begin{array}{l}\text { No berço } \\
\text { (de lado) }\end{array}$ & 44,4 & 33,3 & 44,4 & 33,3 & - & - & - & - & - & - \\
\hline $\begin{array}{l}\text { No bebê } \\
\text { conforto }\end{array}$ & - & - & - & - & - & - & - & 11,1 & - & 11,1 \\
\hline $\begin{array}{l}\text { No carrinho } \\
\text { (deitado) }\end{array}$ & 11,1 & 44,4 & 11,1 & 44,4 & 22,2 & 66,7 & 22,2 & 22,2 & 22,2 & - \\
\hline $\begin{array}{l}\text { No carrinho } \\
\text { (sentado) }\end{array}$ & - & - & - & - & 11,1 & - & - & 11,1 & - & 11,1 \\
\hline $\begin{array}{l}\text { No chão } \\
\text { (barriga p/ baixo) }\end{array}$ & - & - & - & - & - & - & - & - & - & - \\
\hline $\begin{array}{l}\text { No chão } \\
\text { (barriga p/ cima) }\end{array}$ & - & - & - & - & - & - & - & - & - & - \\
\hline No chiqueirinho & - & - & - & - & - & - & - & - & - & - \\
\hline No colo (deitado) & 11,1 & 22,2 & 11,1 & 22,2 & 55,6 & 22,2 & 11,1 & 11,1 & 11,1 & 33,3 \\
\hline No colo (sentado) & - & - & - & - & 11,1 & 11,1 & 22,2 & 11,1 & 22,2 & 22,2 \\
\hline Rede & - & - & - & - & - & - & 33,3 & - & 33,3 & - \\
\hline
\end{tabular}

A Tabela 3 mostra a postura adotada durante o sono. Nota-se que no grupo pré-termo, em recémnascidos e no primeiro mês, a postura adotada para dormir foi o decúbito lateral (55,6\% em ambos os meses); no segundo mês adotou-se a postura prona $(44,4 \%)$. Já os lactentes a termo adotaram a postura em decúbito lateral, de recém-nascido até o segundo mês (100\%); no terceiro mês houve semelhança nas posturas de decúbito lateral e supino $(44,4 \%)$ para os lactentes pré-termo, e a preferência pelo decúbito lateral permaneceu para os lactentes a termo, tanto no terceiro quanto no quarto mês $(77,8 \%)$; no quarto mês, nos lactentes pré-termo, houve semelhança nas posturas prona e supino $(44,4 \%)$. 
Tabela 3 - Caracterização da postura ao dormir em ambos os grupos mensalmente

\begin{tabular}{|c|c|c|c|c|c|c|c|c|c|c|}
\hline \multirow{2}{*}{$\begin{array}{l}\text { Postura } \\
\text { ao dormir }\end{array}$} & \multicolumn{2}{|c|}{$\mathbf{R N}$} & \multicolumn{2}{|c|}{1 mês } & \multicolumn{2}{|c|}{2 mês } & \multicolumn{2}{|c|}{3 mês } & \multicolumn{2}{|c|}{4 mês } \\
\hline & $\begin{array}{l}\% \text { pré- } \\
\text { termo }\end{array}$ & $\begin{array}{c}\% \text { a } \\
\text { termo }\end{array}$ & $\begin{array}{l}\% \text { pré- } \\
\text { termo }\end{array}$ & $\begin{array}{c}\% \text { a } \\
\text { termo }\end{array}$ & $\begin{array}{l}\% \text { pré- } \\
\text { termo }\end{array}$ & $\begin{array}{c}\% \text { a } \\
\text { termo }\end{array}$ & $\begin{array}{l}\% \text { pré- } \\
\text { termo }\end{array}$ & $\begin{array}{c}\% \text { a } \\
\text { termo }\end{array}$ & $\begin{array}{l}\% \text { pré- } \\
\text { termo }\end{array}$ & $\begin{array}{c}\% \text { a } \\
\text { termo }\end{array}$ \\
\hline Barriga para baixo & 44,4 & - & 44,4 & - & 44,4 & - & 44,4 & - & 11,1 & - \\
\hline Barriga para cima & - & - & - & - & 22,2 & - & 11,1 & 22,2 & 44,4 & 22,2 \\
\hline De lado & 55,6 & 100 & 55,6 & 100 & 33,3 & 100 & 44,4 & 77,8 & 44,4 & 77,8 \\
\hline
\end{tabular}

Na Tabela 4 observa-se que, em recém-nascidos e no primeiro mês, todos os lactentes pré-termo permaneceram em casa com as mães. A partir do segundo, uma parte dos lactentes começou a frequentar a creche $(22,2 \%)$; porém, a maioria ainda permaneceu em casa com as mães no decorrer dos quatro meses $\mathrm{O}$ grupo a termo permaneceu em casa com as mães em todos os meses avaliados $(100 \%)$.

Tabela 4 - Caracterização da interação com pessoas em ambos os grupos mensalmente

\begin{tabular}{|c|c|c|c|c|c|c|c|c|c|c|}
\hline \multirow{2}{*}{$\begin{array}{l}\text { Interação } \\
\text { com pessoas }\end{array}$} & \multicolumn{2}{|c|}{$\mathbf{R N}$} & \multicolumn{2}{|c|}{1 mês } & \multicolumn{2}{|c|}{2 mês } & \multicolumn{2}{|c|}{3 mês } & \multicolumn{2}{|c|}{4 mês } \\
\hline & $\begin{array}{l}\% \text { pré- } \\
\text { termo }\end{array}$ & $\begin{array}{c}\% \text { a } \\
\text { termo }\end{array}$ & $\begin{array}{l}\% \text { pré- } \\
\text { termo }\end{array}$ & $\begin{array}{c}\% \text { a } \\
\text { termo }\end{array}$ & $\begin{array}{l}\% \text { pré- } \\
\text { termo }\end{array}$ & $\begin{array}{c}\% \text { a } \\
\text { termo }\end{array}$ & $\begin{array}{l}\% \text { pré- } \\
\text { termo }\end{array}$ & $\begin{array}{l}\% \mathrm{a} \\
\text { termo }\end{array}$ & $\begin{array}{l}\% \text { pré- } \\
\text { termo }\end{array}$ & $\begin{array}{l}\% \mathrm{a} \\
\text { termo }\end{array}$ \\
\hline Mãe & 100 & 100 & 100 & 100 & 77,8 & 100 & 88,9 & 100 & 66,7 & 100 \\
\hline Creche & - & - & - & - & 22,2 & - & 11,1 & - & 33,3 & - \\
\hline
\end{tabular}

$\mathrm{Na}$ Figura 1 pode-se verificar que em ambos os grupos houve aumento progressivo do escore no decorrer dos meses, e não houve diferença significativa entre os grupos com o Teste de Mann-Whitney ( $\mathrm{p} \geq$ 0,050). Porém, ainda com o Teste de Mann-Whitney aplicado nos itens da escala TIMP, constatou-se diferença significativa entre os grupos nos itens $32(p=0,035), 35(p=0,032)$ e $36(p=0,015)$ na idade de $R N$, sendo que o grupo a termo demonstrou desempenho superior ao grupo pré-termo nesses itens.

A Figura 2 mostra a aquisição do escore de pré-termos e a termos durante os meses. Pelo Teste de Mann-Whitney, pode-se verificar que houve diferença significativa entre os grupos de RN para 1 mês ( $\mathrm{p}=$ 0,012) e de 1 mês para 2 meses $(p=0,034)$. De $R N$ para 1 mês, a aquisição do grupo pré-termo foi maior que a do grupo a termo; já de 1 mês para 2 meses, a aquisição do grupo a termo foi maior que a aquisição do grupo pré-termo. 
Pretti LC, Milan JC, Foschiani MA, Raniero EP, Pereira K.

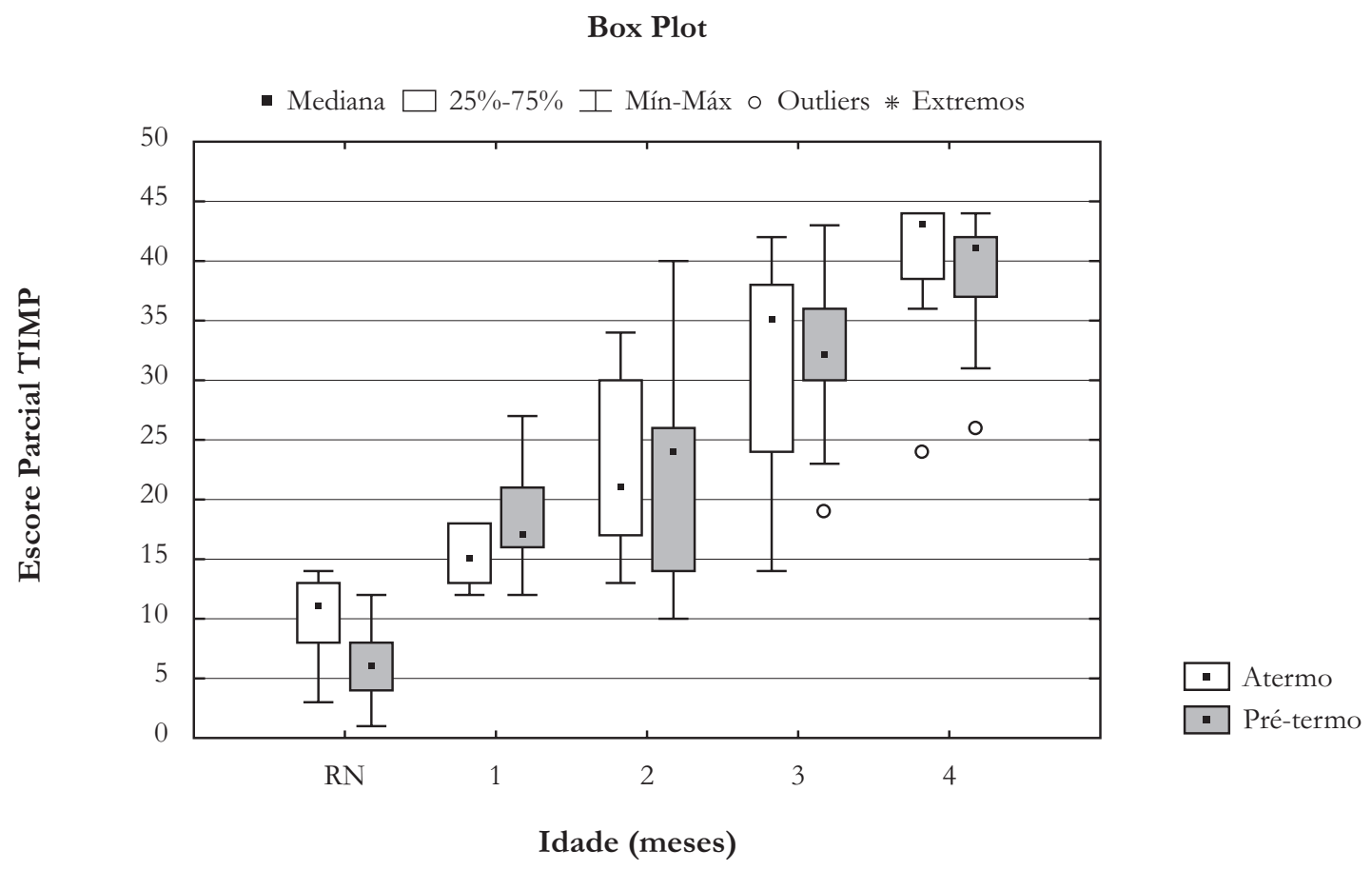

Figura 1 - Escore Parcial da TIMP nos grupo pré-termo e a termo

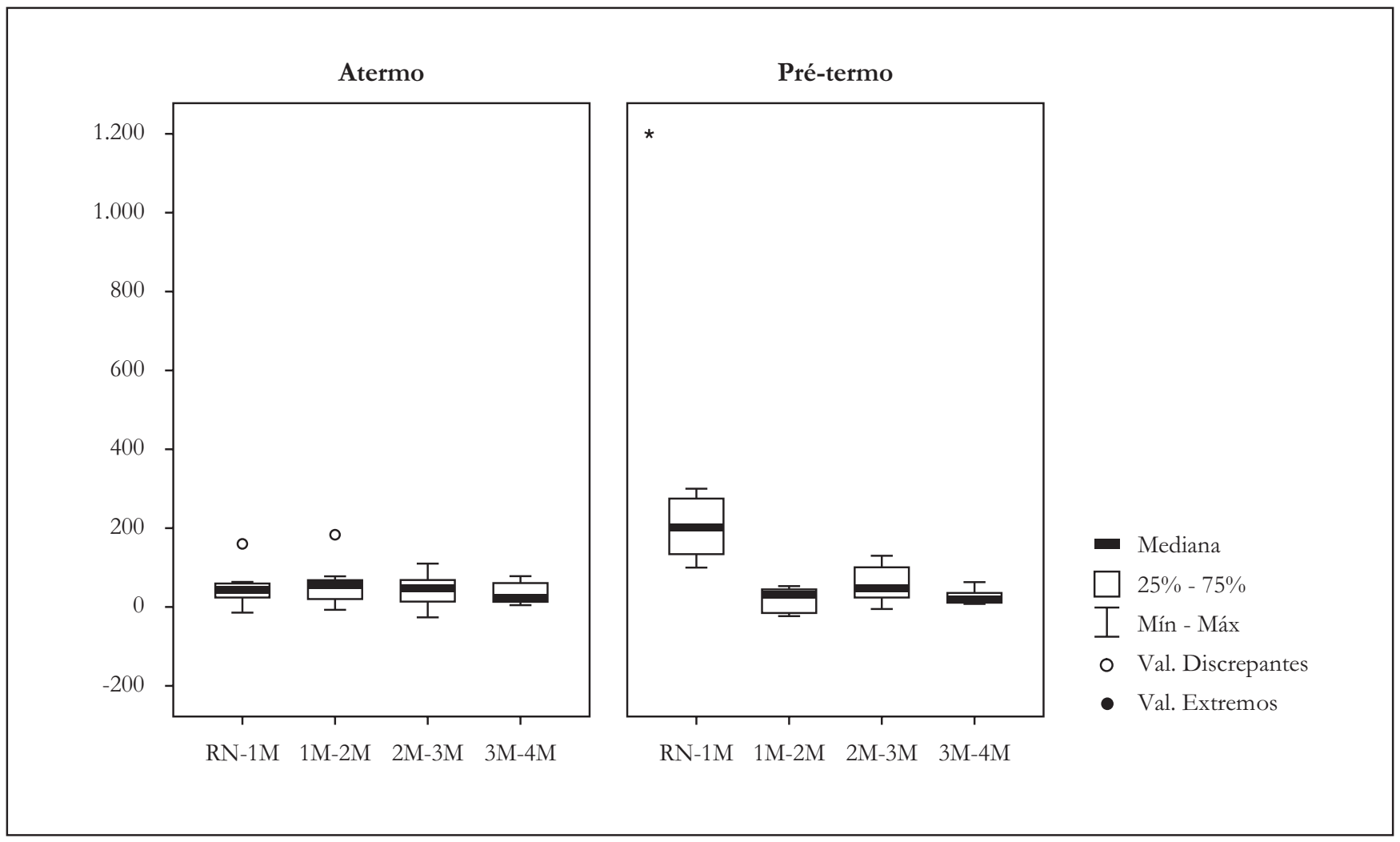

Figura 2 - Diferença na aquisição do controle cervical mês a mês 


\section{Discussão}

O presente estudo evidenciou que as mães do grupo pré-termo apresentaram maior incidência de eventos estressantes durante a gestação que as do grupo a termo. Segundo Gallahue e Ozmun (4), fatores de estresse grave podem estar associados a complicações na gravidez e anormalidades fetais, visto que toda alteração que ocorrer no corpo materno terá seus reflexos no organismo fetal. Eles ressaltam ainda que crianças nascidas de mães emocionalmente estressadas tendem a ser vulneráveis a uma variedade de doenças e problemas físicos no decorrer da vida. Diante dessas considerações, o presente estudo verificou que os lactentes pré-termo de mães que passaram por eventos de estresse apresentaram desempenho motor inferior e lento na avaliação da TIMP em relação ao grupo a termo.

Outro ponto abordado neste estudo foi o uso de nicotina durante a gravidez. O tabagismo materno pode interferir em qualquer idade gestacional, podendo levar ao nascimento de crianças prematuras de baixo peso ao nascer (19). Apesar de pouca diferença de percentis em ambos os grupos, as mães do grupo a termo foram as que mais fizeram o uso de nicotina. Assim, neste estudo a prematuridade não esteve relacionada diretamente ao tabagismo.

$\mathrm{Na}$ realização de atividade física, uma pequena porcentagem de mães de ambos os grupos (33,3\% do grupo pré-termo e $28,6 \%$ do grupo a termo) realizavam algum tipo de atividade física (caminhada regular, por exemplo) durante a gestação. Pijpers, Wladimiroff e Mcghie (20) verificaram que a realização de exercício físico leve e/ou moderado foi saudável para a gestação, visto que não houve alterações significativas nos batimentos cardíacos fetais e nenhum sinal de estresse fetal. Além disso, Lotgering, Gilbert e Longo (21) relatam que as alterações fisiológicas para o feto são pequenas, apesar de ocorrer alterações fisiológicas na mãe que se exercita. Assim, sugere-se que a atividade física não é um fator negativo na prematuridade, isto é, não influencia no parto prematuro.

Quanto à ocorrência de problemas respiratórios, o grupo pré-termo foi o único a apresentar alguma incidência $(22,2 \%)$, o que se explica, segundo Shepherd (10), pelo fato do lactente prematuro apresentar imaturidade do sistema respiratório (infecções ocasionadas por precariedade de defesas imunológicas), circulatório (dimensões reduzidas das vias aéreas) e metabólicas (aumento do metabolismo).

Em relação à alimentação do lactente, foi baixa a prevalência de mães do grupo pré-termo que amamentaram no seio; já no grupo a termo todas as mães amamentaram seus lactentes. Pode-se destacar que o aleitamento materno favorece o vínculo mãe/bebê no desenvolvimento do lactente (22). A prevalência de lactentes pré-termo que fazem o uso de outros meios de alimentação, como NAN e leite em pó, pode ser explicada pelo fato de apresentarem menos habilidade para gerar as alterações de pressão necessárias durante a sucção, pois dependem da integridade dos lábios, da cavidade oral, dos músculos faciais e, também, da magnitude de contração dos músculos geradores de pressão. Portanto, situações ou anomalias que resultem em limitações dessas funções podem comprometer a eficiência do processo ou até mesmo impedir a alimentação por via oral (22).

A dificuldade para adquirir habilidades motoras fundamentais, o atraso na aquisição da linguagem e problemas de coordenação motora têm sido associados a problemas de âmbito socioeconômico $(7,19)$. Neste estudo, o grupo pré-termo apresentou maior porcentagem na classe B (42,9\%) e o grupo a termo na classe C (50\%). Gama, Macedo, Marra, Silva, Matos e Abdallah (19) salientam que nas classes sociais mais baixas os cuidados médicos são inespecíficos, a alimentação é desequilibrada (subnutrição materna e anemia) e o pré-natal, inadequado. Embora o grupo a termo tenha apresentado prevalência na classe C, isso não foi um fator determinante na obtenção do controle cervical, visto que nesse grupo esta aquisição se deu mais efetivamente que no grupo pré-termo, enquadrado em condições socioeconômicas mais elevadas (classe B).

Em relação à postura do lactente em estado de alerta, os resultados do presente estudo apontaram que houve predominância da postura de decúbito lateral, em recém-nascido e 1 mês, no grupo pré-termo, sendo substituído pela postura supina do segundo ao quarto mês, constatando-se que a postura prona foi a menos adotada nesse período. No grupo a termo houve predominância da postura supina nos quatro meses de avaliação. Davis, Moon, Sach e Ottolini (23) e Dewey, Fleming e Golding (24) afirmaram que os lactentes que são colocados em supino, quando em alerta, têm pouco estímulo para desenvolver força da musculatura extensora cervical e de tronco, além de apresentarem atrasos para desenvolver movimentos 
antigravitacionais, deixando de ativar musculaturas da cervical, ombros e tronco, necessárias para potencializar suas aquisições motoras ao longo do desenvolvimento motor. Shriber e Zelazny (6) concluem que os lactentes colocados na posição prona têm estímulos para adquirir habilidades motoras nas demais posições antigravitárias, como a sentada.

A postura adotada para dormir no grupo pré-termo variou entre a de decúbito lateral, adotada na maioria dos meses, e as de prono e supino. Já no grupo a termo predominou a postura de decúbito lateral nos quatro meses de avaliação. Majnemer e Barr (13) concluíram que crianças colocadas em supino para dormir apresentaram atraso no desenvolvimento motor, e este foi intensificado pelo não posicionamento na postura prona quando em alerta, afetando, assim, a aquisição de habilidades motoras. O mesmo foi concluído por Monson, Deitz e Kartin (5).

Segundo a American Academy of Pediatrics (AAP) e o American Sudden Infant Death Syndrome Institute, lactentes que são colocados em prono para dormir podem estar mais propensos a desenvolver a síndrome da morte súbita (6). Porém, segundo Monson, Deitz e Kartin (5), os bebês colocados para dormir em prono estão mais susceptíveis ao desenvolvimento precoce dos marcos motores, pois estes denotam um processo de maturação que corresponde a mudanças funcionais e comportamentais. Em relação à postura sentada, Darrah, Piper e Watt (25) afirmam que somente será alcançada se o lactente apresentar controle de cervical e tronco. Sendo assim, a aquisição da postura sentada pode ser influenciada caso haja alterações no desenvolvimento motor inicial.

Os lactentes pré-termo, de recém-nascido até 1 mês, eram exclusivamente cuidados pelos pais; a partir do segundo mês, passaram a interagir com outros ambientes, como a creche. Andraca, Pino, La Pana, Riviera e Macela (26) afirmam que a responsividade da mãe em relação às demandas do bebê e sua capacidade de envolver-se com ele tem efeito significativo sobre o desempenho motor e cognitivo. Segundo Bofi (27), a partir da inclusão da creche no sistema educativo, a concepção de uma instituição dirigida para uma ação educativa promotora do desenvolvimento infantil começa a ser valorizada. Assim, aspectos como estimulação, interação, recreação, etc. passam a ser destacados como elementos fundamentais para o desenvolvimento neuro-sensório-motor. Diversas situações na creche são construtivas para o desenvolvimento, pois gradativamente a criança vai deixando a passividade e tornando-se mais ativa. É por meio da rotina que a criança realiza suas trocas com as pessoas e o ambiente exterior. É assim que a criança vai realizando seu aprendizado, constituindo seu eu e desenvolvendo seu corpo (27-29).

O presente estudo permitiu identificar, por meio do TIMP, que não houve diferenças significativas no desenvolvimento do controle cervical entre os grupos no decorrer dos meses, mas os lactentes nascidos a termo apresentaram escore superior aos pré-termo nos itens 32, 35 e 36 da escala TIMP na idade de RN. Mancini et al. dizem em seu estudo que a prematuridade é um fator de risco que pode interferir na aquisição de etapas motoras relativas ao ritmo e padrões de aquisição durante o primeiro ano de vida, diferindo-se assim dos nascidos a termo. Diz ainda que os lactentes nascidos pré-termo diferem daqueles nascidos a termo, em relação ao tônus muscular, reflexos primitivos e reações posturais, principalmente nos primeiros meses de vida (30).

\section{Considerações finais}

Assim, conclui-se que apesar de haver uma ligeira diferença na aquisição do controle cervical dos lactentes nascidos pré-termo, foi verificada pouca diferença no percentil da escala TIMP entre os grupos, sugerindo que este pode ter apresentado escore inferior em decorrência das alterações orgânicas (desequilíbrio muscular) que os lactentes apresentam nos primeiros 4 meses de idade. Pode-se sugerir também que os fatores ambientais observados no presente estudo podem ter colaborado para as variações de aquisição do controle cervical de RN até os 3 meses de idade. Contudo, não foi realizado nenhum teste estatístico para comprovação da influência, pois é necessária uma amostra maior de lactentes para verificar se os fatores ambientais influenciam no desenvolvimento do controle cervical dos lactentes nascidos pré-termo, de recém-nascidos até os 4 meses de idade, e dentre eles quais são mais efetivos. 


\section{Referências}

1. Rosengren K, Savelsbergh GJP, Van Der Kamp J. Development and learning: a TASC-based perspective of the acquisition of perceptual-motor behaviors. Infant Behavior \& Develop. 2003;26(4):473-94.

2. $\quad$ Newell KM. Motor skill acquisition. Ann Rev Psychol. 1991;42:213-37.

3. Von Hof P, Van Der Kamp J, Caljouw SR, Savelsbergh GJP. The confluence of intrinsic and extrinsic constraints on 3 to 9-month-old infants' catching behavior. Infant Behavior \& Develop. 2005;28:179-93.

4. Gallahue DL, Ozmun JC. Compreendendo o desenvolvimento motor: bebês, crianças, adolescentes e adultos. 2a ed. São Paulo: Phorte; 2003.

5. Monson RM, Deitz J, Kartin D. The relationship between awake positioning and motor performace among infants who slept supine. Pediatr Phys Ther. 2003;15(4):196-203.

6. Shriber LD, Zelazny S. The effects of prone positioning on the quality and acquisition of developmental milestones in four-month-old infants. Pediatric Physical Therapy. 2007;19(1):48-55.

7. Tavares EC, Rego MAS. Prematuridade e retardo de crescimento. In: Lopez FA, Junior DC. (Org.). Tratado de Pediatria. Barueri (SP): Manole; 2007. p. 1315-23.

8. Linhares MBM, Carvalho AEV, Machado C, Martinez FE. Desenvolvimento de bebês nascido pré-termo no primeiro ano de vida. Cadernos de Psicologia e Educação - Paidéia. 2003;13(25):57-72.

9. Carvalho AEV, Linhares MBM, Martinez FE. História de desenvolvimento e comportamento de crianças nascidas pré-termo e baixo peso (< 1.500g.). Psicologia: Reflexão e Crítica. 2001;14(1):1-33.

10. Sheperd RB. Fisioterapia em Pediatria. Hildegard Thilmann Buckup Tradutor. São Paulo: Livraria Santos; 1998.

11. Restiffe AP, Gherpelli JLD. Comparison of chronological and corrected ages in the gross motor assessment of low-risk preterm infants during the first year of life. Arq Neuropsiquiatr. 2006;64(2B):418-25.

12. Mancini MC, Carvalho DJ, Gontijo DT. Os efeitos da correção da idade no desempenho motor grosso e fino de crianças pré-termo aos dois anos de idade. Temas Desenvolv. 2002;11(64):12-9.

13. Majnemer A, Barr R. The influence of supine sleep position on early motor milestone acquision. Dev Med Child Neurol. 2005;47:370-6.

14. Campbell SK. The test of infant motor performance - test user's manual version 1.4. Chicago: Infant Motor Performance Scales; 2001.

15. Gonçalves AL, Martinez FE, Ferlim ML, Mussi Pinhata MM, Jorge SM. Rotinas médicas em neonatologia. Ribeirão Preto: HCFMRP-USP; 2006. p. 18-21.

16. Madi JM, Morais EM, Locatelli E, Madi SRC, Rombaldi RL. Síndrome de aspiração do mecônio: análise de resultados obstétricos e perinatais. Rev Bras Ginecol Obstet. 2003;25(2):123-8.

17. Brazelton TB. Neonatal behavioral assessment scale. Philadelphia: J.B. Lippincott Co; 1984.

18. Associação Brasileira de Institutos de Pesquisa de Mercado - ABIPEME. Anexo 3 - Classificação Socioeconômica - Critério ABIPEME. [capturado 23 mar. 2007]. Disponível em: www.ufrn.br

19. Gama PR, Macedo LA, Marra EVO, Silva VC, Matos CLC, Abdallah VOS. Relação entre prematuridade e o baixo peso ao nascer com o nível socioeconômico, tabagismo materno e ingestão de álcool durante a gravidez. Revista eletrônica. [capturado14 out. 2007]. Disponível em: http://www.propp.ufu.br/revistaeletronica/vida2003/Relacao.pdf

20. Pijpers L, Wladimiroff JW, Mcghie J. Effect of short-term maternal exercise on maternal and fetal cardiovascular dynamics. Br J Obstet Gynaecol. 1984;91(11):1081-6. 
21. Lotgering FK, Gilbert RD, Longo LD. Maternal and fetal responses to exercise during pregnancy. Physiol Rev. 1985;65(1):1-36.

22. Xavier C. Trabalho fonoaudiológico em berçário. In: Lopez Filho O. Tratado de Fonoaudiologia. São Paulo: Roca; 1997. p. 1001-23.

23. Davis BE, Moon RY, Sachs HC, Ottolini MC. Effects of sleep position on infant motor development. Pediatrics. 1998;102(5):1135-40.

24. Dewey C, Fleming P, Golding J. Does the supine sleep position have any adverse effects on the child? Pediatrics. 1998;101(1):51-5.

25. Darrah J, Piper M, Watt MJ. Assessment of gross motor skills of at-risk infants: predictive validity of the alberta infant motor scale. Dev Med Child Neurol. 1998;40(7):485-91.

26. Andraca I, Pino P, La Pana A, Riveira F, Castillo M. Factores de riesgo para el desarrollo psicomotor em lactentes nascidos en óptimas condiciones biológicas. Cad Saúde Pública. 1998;32(2):138-47.

27. Bofi TC. O atendimento infantil nas creches de Presidente Prudente - área do desenvolvimento sensório-motor. Presidente Prudente; 2000. [dissertação] - Universidade do Oeste Paulista, São Paulo, 2000.

28. Abramovicz A, Wajskop G. Creches: atividades para crianças de zero a seis anos. São Paulo: Moderna; 1991.

29. Barbosa AA. Educar e cuidar: a transformação do educador de creche frente às novas exigências. Comunicação. 1998;5(2):133-9.

30. Mancini MC, Teixeira S, Araújo LG, Paixão ML, Magalhães LC, Coelho ZAC, et al. Estudo do desenvolvimento da função motora aos 8 e 12 meses de idade em crianças nascidas pré-termo e a termo. Arq Neuropsiquiatr. 2002;60(4):974-80.

Recebido: 03/03/2009

Received: 03/03/2009

Aprovado: $10 / 02 / 2010$

Approved: 02/10/2010

Revisado: $10 / 05 / 2010$

Reviewed: 05/10/2010 